\title{
Políticas neoliberais: o desaparecimento de pessoas na burocracia dos cemitérios
}

\author{
Neoliberal policies: the disappearance of persons in the cemetery \\ bureaucracy
}

\section{RESUMO}

O presente artigo reflete sobre diferentes processos de desaparecimento de pessoas no contexto contemporâneo. Analisa outras formas de desaparecimento, que não seja forçado, cujas pesquisas têm desvelado suas diferentes estratégias, formas e ações. Por intermédio das complexas relações entre ação e omissão do Estado, em seus diferentes níveis e políticas neoliberais de concessões ou privatizações dos serviços cemiteriais, procuramos refletir sobre formas de desaparecimento de pessoas pela burocracia. A partir de um contexto na cidade de São Paulo - Brasil, procura-se evidenciar como esse fato não está relacionado apenas a uma ação individual ou a um erro particular, mas, também, a uma política de governo que não provê as necessidades básicas de parte da sociedade, então escolhida à própria perda de sua identidade.

Palavras-chave: Cemitério - Desaparecimento - Burocracia - Violência de Estado - Antropologia forense

\section{ABSTRACT}

This article explores different processes of the disappearance of people in the contemporary context. It is proposed to investigate other methods of disappearing, beyond the forced disappearance of persons, whose numerous investigations have revealed their different strategies, forms, and actions. Through the complex relationship between the action and the omission of the State at its different levels and the neoliberal policies for concessions or privatization of cemetery services, we attempt to reveal, from a context in the city of São Paulo - Brazil, ways of making disappear persons through the bureaucracy. We explore how this phenomenon is related not only to an individual action or to a particular error, but also to a government policy that does not satisfy the basic needs of society, then chosen due to the loss of its identity.

Keywords: Cemetery - Disappearance of persons - Bureaucracy - State Violence - Forensic Anthropology

* Doutoranda em Estrategias Científicas Interdisciplinarias en Patrimonio y Paisaje, Universidad del Pais Vasco, EHU, Espanha. Mestre em Arqueologia pelo Museu de Arqueologia e Etnologia da Universidade de São Paulo. Desde 2013 atua em projetos de Antropologia Forense pela Comissão Especial sobre Mortos e Desaparecidos Políticos - CEMDP. Entre 2014 e 2017 coordenou a pesquisa preliminar e ante mortem nas atividades do Grupo de Trabalho criado pela Secretaria de Direitos Humanos da Presidência da República com a finalidade de proceder à análise de restos mortais oriundos do Cemitério de Perus, São Paulo - SP, com vistas à identificação de mortos e desaparecidos políticos assim reconhecidos pela Lei 9.140/95. CV: <http://lattes.cnpq.br/2096704131182642>

** Doutoranda e Mestre, em Direito Penal, pela Pontifícia Universidade Católica de São Paulo. Atualmente, é Professora Assistente Mestre de Graduação e professora da Pós-graduação Lato Sensu de Direito Penal, na Pontifícia Universidade Católica de São Paulo, bem como Professora convidada, na Pós-graduação Lato Sensu da Escola Superior do Ministério Público do Estado de São Paulo. É Promotora de Justiça do Ministério Público do Estado de São Paulo desde 1997, hoje 114a Promotora de Justiça Criminal da Capital, ora assessorando a Procuradoria-Geral de Justiça na coordenação do PLID - Programa de Localização e Identificação de Desaparecidos. CV: <http://lattes.cnpq.br/3322639444839350> 


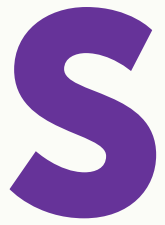

egundo o registro do cemitério Quarta Parada, João da Silva ${ }^{1}$ era um homem negro, que morreu de traumatismo cerebral aos 28 anos de idade. Seu laudo de necrópsia foi produzido por um médico legista, do Instituto Médico Legal de São Paulo IML-SP. Dois dias após sua morte, foi enterrado na Quadra Geral 7, sepultura 16, no ano de 1978. Este cemitério, no qual João foi inumado, está localizado na zona leste da cidade de São Paulo, e é um dos cemitérios públicos mais antigos, inaugurado no final do século XIX. Localizado no bairro do Brás, que foi um dos bairros mais populosos da cidade, majoritariamente com operários. Esses trabalhadores foram os primeiros a ocupar o que se denominava então a quadra geral, espaços do cemitério para aqueles que não tinham recursos para comprar um jazigo no cemitério, mas moravam próximo e deviam ser enterrados em algum lugar. Estas quadras gerais são regulamentadas pelo município, que deve "conceder gratuidade dos serviços de sepultamento e dos meios e procedimentos a ele necessários, bem como dos serviços de exumação e dos meios a ele necessários, à população de baixa renda".2

Na metade dos anos 1990, essa quadra geral deixou de existir no cemitério mencionado e seu espaço foi colocado à venda, alegado como essencial à continuidade das inumações particulares. Nesse contexto, todos que estavam nas quadras gerais foram exumados. Com a readequação do espaço, a administração municipal passou a ter estrito controle sobre os remanescentes humanos esqueléticos das quadras gerais, a serem remanejados por: identificação nominal ou não e, na primeira hipótese, acompanhados ou não pela família, proprietária dos despojos e inequivocamente informada de seu destino.

No caso dos identificados, seus destinos seriam um jazigo da família, agora particular; um espaço nos ossários individuais localizados nas paredes do cemitério; o translado para outro cemitério ou, na ausência da família informada, o ossário geral/coletivo. Já corpos de pessoas não identificadas seguiriam ao ossário geral/coletivo. Ocorre que a administração não só não contava com esses registros básicos iniciais, bem como deixou de fazer outros registros no momento dos traslados, protagonizando o desaparecimento de corpos.

João da Silva sequer teve o registro do destino final de seu corpo no denominado "livro de entrada do cemitério". Este documento controla todos os registros e movimentos das pessoas ali enterradas. Segundo o livro, ele foi enterrado e nunca foi exumado. João não pode estar enterrado no mesmo lugar. Não há informações sobre seu destino, mesmo sabendo que seus remanescentes humanos ósseos foram movidos. João desapareceu na burocracia do cemitério. Ele foi enterrado com seu nome e sobrenome em uma quadra geral, mas, após anos o cemitério perdeu a localização de seu corpo, pelo simples fato de não registrar a movimentação do corpo. Como isso ocorre? Como podemos compreender esse mecanismo e qual sua origem? Noutros casos, presenciados por nós no mesmo cemitério, várias ossadas foram encontradas no espaço destinado ao ossário geral, acondicionadas de forma prejudicial a futuras perícias antropológicas, pois muitos não estavam identificados e, quando sim, sem qualquer documentação para comprovar ciência da família.

\footnotetext{
1 Nome fictício.

2 Ver Artigos 79 e 80. SÃO PAULO. Decreto Municipal no 59.196, de 29 de janeiro de 2020. Regulamenta os serviços funerários, cemiteriais e de cremação no Município de São Paulo. Diário Oficial Cidade de São Paulo, São Paulo, ano 65, n. 20, p. 1, 30 jan. 2020.
} 
O objetivo deste artigo é desenvolver uma reflexão sobre o desaparecimento dentro de instituições estatais, no contexto contemporâneo. Trata-se de analisar outras formas de desaparecer que não mediante desaparecimento forçado de pessoas, cujas inúmeras pesquisas têm desvelado suas diferentes estratégias, formas e ações. Por intermédio das complexas relações de políticas neoliberais de concessões ou privatizações dos serviços cemiteriais a atender, como não poderia deixar de ser, os interesses empresariais, refletimos, a partir de um contexto na cidade de São Paulo - Brasil, formas de desaparecimento de pessoas pela burocracia. Busca-se evidenciar como esse fato não está associado apenas a uma ação individual ou a um erro particular, mas, também, a uma política de Estado que não provê as necessidades básicas de uma parcela da sociedade, então escolhida à própria perda de sua identidade.

\section{Formas de desaparecer}

Nasúltimas décadas, uma intensa produção acadêmica tem se voltado para a investigação dos desaparecimentos, muitos impulsionados pelos próprios movimentos sociais em diferentes partes do mundo. Esses movimentos protagonizados especialmente por mulheres, familiares de desaparecidos, foram propulsores para investigar e pressionar organismos internacionais, Estados, pesquisadores e sociedade civil, seja no passado ou no presente. Reconhecidas no mundo todo, o movimento das Mães de Maio na Argentina protagonizou essa luta e apoiou grande parte dos avanços nas pesquisas sobre desaparecimento forçado no mundo, ao fomentar diferentes pesquisas e trabalhos em distintas áreas, como Antropologia, Genética, Arqueologia, História, Sociologia, Direito, entre tantos outros campos de conhecimento que lidam com a temática. No Brasil não foi diferente. O protagonismo dos grupos de familiares e militantes de direitos humanos, como a Comissão de Familiares de Mortos e Desaparecidos Políticos, os Grupos Tortura Nunca Mais do Rio de Janeiro, Bahia, Pernambuco, entre tantos outros, foram fundamentais na luta pela memória, verdade e Justiça (Teles, 2001; 2010)

Podemos afirmar que, especialmente em relação ao desaparecimento forçado de pessoas em contextos ditatoriais ou de conflitos, uma vasta produção que envolve des de histórias de vida, estratégias da repressão, estudos de centros clandestinos, campos de concentração, e a investigação forense têm sido realizadas, não apenas no continente americano, como na África, Ásia e Europa. No Brasil, especialmente na área da História e do Direito, inúmeros estudos foram desenvolvidos, devotados sobretudo aos processos relacionados à justiça de transição (Abrão e Torelly, 2010), à lei da anistia, história oral de vida de ex-presos políticos, e também da Arqueologia de centros clandestinos (Baretta, 2014) e de Antropologia Forense, como é o caso das pesquisas no cemitério Ricardo de Albuquerque e Perus (Coimbra e Brasil, 2009; Teles e Lisboa, 2012).

Por outro lado, ainda há muito por fazer, pois muitos arquivos militares não foram abertos.

É necessário desvelar e compreender as estratégias repressivas dirigidas ao desaparecimento 
de pessoas ${ }^{3}$, casos forenses a serem realizados de maneira sistemática, como é o da Guerrilha do Araguaia, Foz do Iguaçu, Casa da Morte e tantos outros potenciais lugares de inumação. Soma-se a este quadro o fato que os estudos sobre casos de desaparecimentos de indígenas e camponeses no Brasil, durante a ditadura, ainda são incipientes e poucos são os avanços em sua investigação. Os principais trabalhos que envolveram o reconhecimento do Estado nas violações de direitos humanos foram a partir da Comissão da Anistia (Abrão e Torelly, 2010), da Comissão Nacional da Verdade ${ }^{4}$ e por iniciativa de alguns pesquisadores (Valente, 2017; Maguire, 2019).

O século XX é caracterizado como o século em que fomos capazes de aparelhar e estruturar a destruição em massa. O século da destruição, como alguns denominam, herda muito do passado, razão pela qual pesquisadores como Marc Augé (2007) o nomeiam como supermodernidade, e não como pós-moderno, já que não há uma ruptura, senão um incremento no que caracterizou a modernidade, período em que ocorre o maior deslocamento forçado de pessoas já realizado em escala mundial - a de africanos escravizados ao continente americano.

Tais referências são relevantes, pois quando tratamos destes temas é fundamental pensar sobre as raízes históricas e o aparelhamento das instituições, e as formas de lidar com diferentes categorias de cidadãos, que temos como herança no presente. É sobre o contexto contemporâneo que buscamos refletir aqui, sobre as diferentes formas de desaparecer com corpos da atualidade. Uma parcela delas é fundamentada em uma herança de tecnologias e aparelhamentos institucionais provenientes da ditadura. No processo da redemocratização e na justiça de transição não foram repensadas no âmbito das instituições, em que antes integravam no aparato repressivo (Hattori, 2020). Quando abordamos de formas diferentes de tratamento em relação a quem tem mais direitos, não há como não refletir acerca das raízes históricas brasileiras que entrecruzam raça, classe e gênero.

Quando nos referimos ao desaparecimento no contexto contemporâneo brasileiro a que nos remetemos? Desaparecimento forçado? Desaparecimento administrativo ou por omissão? Desaparecimento de pessoas? Atualmente, essas diferentes categorias se entrecruzam, seja pela omissão do Estado no tratamento de remanescentes humanos, seja pelo desaparecimento forçado por grupos do Estado (como milícias ou por grupos paramilitares). A categorização é complexa, ao se tratar do desaparecer. As pessoas desaparecidas ou dadas por desaparecidas são aquelas das quais os familiares não têm notícia, ou cujo desaparecimento ocorre devido a um conflito armado ou de violência interna. ${ }^{5}$ Recente Lei Federal brasileira define - Lei n. 13.812/2019: "pessoa desaparecida: todo ser humano, cujo paradeiro é desconhecido, não importando a causa de seu desaparecimento, até que sua recuperação e identificação tenham sido confirmadas por vias físicas ou científicas". ${ }^{6}$

3 HATTORI, Márcia Lika; TAUHYL, Ana Paula M. Relatório sobre a documentação do Instituto Médico Legal de São Paulo e os possíveis casos suspeitos relacionados a Aluizio Palhano Pedreira Ferreira. São Paulo: Comissão Especial sobre Mortos e Desaparecidos Políticos, 2017. 39 p.

4 COMISSÃO NACIONAL DA VERDADE. Relatório Final da Comissão Nacional da Verdade. Brasília: CNV, 2014.3 v.

5 Comitê Internacional da Cruz Vermelha - CICV. Disponível em: <https://www.icrc.org/pt/pessoasdesaparecidasbrasil> Acesso em 20 de abril de 2020

6 BRASIL. Lei no 13.812, de 16 de março de 2019. Institui a Política Nacional de Busca de Pessoas Desaparecidas, cria o Cadastro Nacional de Pessoas Desaparecidas... Diário Oficial da União: seção 1-Extra, Brasília, DF, n. 52-A, p. 1, 18 mar. 2019 
O desaparecimento é físico e também social, apaga ambas as esferas de existência de uma pessoa (Baraybar e Blackwell, 2012) e suas consequências afetam não só aquele que desaparece, mas todo seu entorno. Nesse sentido, o desaparecimento e seus efeitos marcam uma comunidade, diante da falta de clareza da maneira como são realizados os procedimentos de investigação, a atuação, a insegurança e a sensação de impunidade. Diante da significativa invisibilidade vivenciada pela grande maioria das famílias e a falta de qualquer repercussão desses casos, são muitos familiares que passam a padecer de enfermidades ou, em situação extrema, mas não incomum, falece.

As diferentes tecnologias de desaparecer com corpos demandam ainda uma materialização institucional ampla e complexa, pautada em instituições, normas, leis, pessoas encarregadas, uma estrutura física e administrativa. Tal estrutura está presente não só em contextos como no Holocausto com a criação de centros de extermínio, como também nas ditaduras latino-americanas e em conflitos contemporâneos. Essas estruturas materiais e práticas utilizadas por funcionários e instituições, que nos interessa desvelar para compreender as complexidades de um tipo de desaparecimento, que é aparelhado pelas instituições estatais sob uma aura de legalidade, nas quais aparentemente os procedimentos necessários para identificação são realizados.

Vale sublinhar a diferença entre o período da ditadura, que durou até 1985 no Brasil e o período democrático posterior a essa data. Como afirmam Teles e Safatle (2010), explorar as continuidades não significa cometer o erro primário de confundir a nossa democracia com uma ditadura, mas lembrar da origem de nossa experiência democrática. A brutalidade das democracias foi sempre abafada. Desde suas origens, as democracias modernas sempre demonstraram tolerância para com certa dose de violência política. As democracias se integraram em sua cultura, formas de brutalidade que recaíram sobre uma série de instituições privadas que atuam fora do Estado, milícias etc.

Formado diante dos inúmeros casos de desaparecimento no Estado de São Paulo, o Programa de Localização e Identificação de Desaparecidos do Ministério Público, durante os anos de 1999 a 2014, descobriu que pessoas foram dadas como desaparecidas no Estado de São Paulo, mas já haviam passado por instituições públicas de necropsia. Segundo Vendramini Carneiro e Gennari (2016), toda vez que desaparece alguém, sobrevém àqueles que procuram, dentre outros tantos sentimentos aterrorizantes, a ideia da morte. Segundo as autoras, toda vez que ocorre um desaparecimento é necessário realizar uma peregrinação por diferentes instituições, e isto é relegado à própria família ou amigos, já que as instituições não têm formas de cruzar os dados.

A iniciar por hospitais mais próximos e findar no conhecido Instituto Médico Legal - IML. Essa busca costuma ser frustrada: ora porque não verificamos um protocolo ou um fluxograma comum aos serviços de saúde para atendimento dessas familias; ora porque as 72 unidades do IML, pelo menos no Estado de São Paulo, não possuem um cadastro fotográfico digital e unificado, o que causa muitas falhas no atendimento. Ainda assim, as famílias precisariam buscar o Serviço de Verificação de Óbito - SVO, mas, como a maciça maioria da população brasileira, 
desconhecem esse serviço (Vendramini Carneiro; Gennari, 2016, p. 41).

Algumas características que estão sendo evidenciadas em pesquisas relacionadas ao desaparecimento por omissão como uma das técnicas utilizadas, podemos verificar:

1. O ar de legalidade na produção de documentos que teriam como primeiro objetivo a identificação, e que ao fim acabam por não serem preenchidas (Ferreira, 2009; Gupta, 2012)

2. Raça, gênero e classe - as moralidades situadas na classificação dos mortos (Medeiros, 2016; Kant de Lima, 1995; Alves, 2011)

3. A não rastreabilidade - a rede de instituições que não dialogam (Vendramini Carneiro e Gennari, 2016; Hattori et al., 2016)

\section{Políticas neoliberais, privatizações e estados de emergência neste contexto}

Em um contexto desigual em que são estabelecidas diferentes moralidades para categorias de cidadãos, quando alguns merecem ser procurados, enquanto e outros não, há inúmeros casos em que a ação e a omissão do Estado se fazem presentes, como tal situação "potencializa" ou complexifica-se em um contexto de políticas neoliberais e privatizações? E em contextos de estado de emergência? Como se pensa a gestão dos mortos?

Consideramos que essa forma, a do desaparecimento burocrático, talvez seja um dos maiores "sucessos" da ordem neoliberal. Em outros termos, significa a capacidade de fazer desaparecer sem problema moral e prático, que implica um assassinato planejado (González Ruibal, 2020). Nosso objetivo aqui é mostrar como diferentes campos disciplinares, como a Antropologia, Arqueologia e o Direito podem contribuir para evidenciar tais formas de ação do Estado, a partir de seus aparatos.

A história de vários "João da Silva" continua com a descoberta, no Cemitério da Quarta Parada, de que todas, simplesmente todas as ossadas que estavam, sem qualquer organização, despejadas (não alocadas) no que se convencionou apontar como o "ossário geral" dali, seriam incineradas, não fosse a reação do Programa de Localização e Identificação de Desaparecidos e a Sociedade Civil Organizada junto ao Poder Judiciário. Foi então pedido que verificassem o local, antes de sua açodada autorização, pois não era lícita a cremação de corpos não identificados. A prefeitura, então visando "limpeza" dos cemitérios, para êxito em sua concessão, havia mentido ao Judiciário, solicitando incinerar ossadas de pessoas identificadas, cujos familiares não teriam mais interesse! Ora, havia ali muitas ossadas não identificadas. Quando pedidas as provas documentais de ciência das demais famílias, a administração municipal recuou e desistiu de todas as cremações, impossibilitada de apresentar as provas!?

Assim, há uma complexificação e uma utilização de diversos aparatos para tanto -

Processo no 0016205-71.2018.8.26.0100, que tramitou perante a 2ª . Vara de Registros Públicos da Comarca Central da Capital de São Paulo. 
no caso das políticas neoliberais de privatização total da cidade de São Paulo, inclusive seus cemitérios. A gestão dos mortos se soma ao uso dos remanescentes humanos ou à sua eliminação para transformar seus espaços em mais rentáveis e atrativos, para investimento do empresariado. Assim, os primeiros a serem eliminados são os não reclamados e não identificados.

Por outro lado, em contextos de estados de emergência, como ocorre na pandemia da Covid-19, inúmeras notas e recomendações foram elaboradas e assinadas por diferentes coletivos e instituições, relacionados aos casos de pessoas não identificadas ou não reclamadas, diante da situação de emergência sanitária. Com o aumento do número de casos positivos de Covid-19, o governo brasileiro, assim como diferentes Estados do mundo, propuseram ações para uma gestão dos corpos de falecidos pela doença. Algumas medidas associadas à rápida inumação ou outras formas, como a cremação, para menor risco de contaminação foram tomadas. Em muitas partes do mundo, familiares não puderam realizar rituais de enterramento, e formas alternativas de despedida do ente querido foram realizadas quando possíveis, de maneira virtual, com mediação de trabalhadoras e trabalhadores da saúde, como na Espanha e na Itália. ${ }^{8}$ Ainda assim, o estresse pós-traumático somado ao luto são desafios debatidos por psicólogos.

Nos casos de pessoas desaparecidas, são os familiares que realizam a busca de seu ente querido em cada instituição - hospitais, diferentes IMLs e delegacias. Em um contexto em que as pessoas em confinamento não podem estar na rua, o número de corpos não reclamados pode se tornar mais alto, e se estes são cremados ou os documentos necessários não são produzidos, a possibilidade de desaparecimentos será crescente, cujos remanescentes humanos serão difíceis de rastrear. Nessa situação de emergência sanitária, a Covid-19 pode aumentar exponencialmente, a números indecifráveis as fraturas e fissuras previamente existentes nesse sistema.

Embora sejam necessárias medidas excepcionais, os direitos fundamentais não podem ficar à margem das determinações dos Poderes da República, como ocorreu com a Portaria Conjunta 01/2020, do Conselho Nacional de Justiça e do Ministério da Saúde do Brasil, que atenta para a necessidade de cuidado com a identificação do paciente internado por Covid-19, a destacar aquele sem nome, devendo ser anotada a estatura ou medida do corpo, cor da pele, sinais aparentes, idade presumida, vestuário e qualquer outra indicação que possa auxiliar seu reconhecimento, além de fotografia da face e impressão datiloscópica do polegar, mas tudo "na medida das possibilidades do serviço de saúde". É a primeira vez, após a vigência da lei federal de 2019 (que exige um banco de dados nacional de desaparecidos - até hoje inexistente) que os olhares do Executivo, de fato, voltam-se para esta temática. Contudo,

8 BBC News Mundo. "El derecho a decir adiós", la conmovedora campaña en Italia para que los pacientes que están a punto de morir puedan despedirse de los suyos. BBC News Mundo, on-line, 21 mar. 2020. Disponível em: $<$ https://www.bbc.com/mundo/noticias-51979714>. Acesso em:15 abr. 2020; BBC News Mundo. Coronavirus: "Tuve que ponerle el teléfono en la oreja a un paciente para que su hija se despidiera de él". BBC News Mundo, on-line, 25 mar. 2020. Disponível em: <https://www.bbc.com/mundo/noticias-52023593>. Acesso em: 15 abr. 2020; CARRETERO, Nacho. Las despedidas pendientes. Las familias no pueden acompañar a los enfermos, ni organizar los velatorios de las víctimas. El País, on-line, 23 mar. 2020. Disponível em: <https://elpais.com/ sociedad/2020-03-22/las-despedidas-pendientes.html>. Acesso em:15 abr. 2020. 
talvez pela ausência de uma política pública permanente, Estados e Prefeituras não atendem a portaria, nem após recomendação oficial do Ministério Público, calcando-se na exceção permissiva da expressão "na medida de suas possibilidades". Ao nosso ver, trata-se de não descuidar da vida a ser salva ali, e não deveria estar ocorrendo. O profissional que cuida desse dado pode ser de área administrativa e contar com um banco de dados ora oferecido pelo SINALID - Sistema Nacional de Localização e Identificação de Desaparecidos, que permite registro digital, rápido e com possibilidade de busca no futuro (sem ser preciso recorrer aos arquivos de cada hospital), o que não tem sido ponderado.

Não parece razoável que a mesma portaria autorize cremação de corpos, na medida em que o Brasil tem postergado a lavratura do registro civil de óbito. As prevenções sanitárias deveriam ser outras, e não dar cabo à possibilidade de reexame do corpo, quando pendente dúvida da causa da morte. Nunca é demais afirmar que o Brasil conta com inumações oficiais, com dados falsos (como destacamos), mas também com inumações não oficiais (em cemitérios clandestinos), que podem, nesse vácuo, contar com cremação oficial.

\section{Formas de resistência - sociedade civil e agentes do Estado}

Formas de resistência da sociedade civil e também no Estado foram e são fundamentais nos esforços contra o desaparecimento. Tais esforços vão além da busca ou do enfoque ao corpo - no caso do cemitério Quarta Parada e as políticas neoliberais na reordenação da administração dos cemitérios públicos, os próprios sepultadores são exemplos de formas de cuidado no cotidiano. São esses os demandados todos os dias para saber a localização de um sepultamento, mesmo sem os materiais e equipamentos para ajudá-los na delimitação das sepulturas. São eles que fazem a separação, segundo uma lógica tradicional que remonta séculos, e a relação dos cemitérios com a igreja católica, de quadras específicas para crianças e recém-nascidos com os adultos. Também são parte do Estado e fazem frente a esses mecanismos de desaparecer.

Por outro lado, no cemitério Quarta Parada, movimentos sociais se organizaram, não só para uma ação contra a Prefeitura ${ }^{9}$, como também para mobilizações organizadas por diferentes movimentos sociais, que envolveram a elaboração de um abaixo assinado, intitulado "Pela Dignidade dos Mortos na Cidade de São Paulo", além de manifestações no próprio cemitério (Figura 1). Em todos esses processos, famílias das vítimas, inclusive de outros Estados, nunca são desamparadas pela Organização não Governamental Mães da Sé, sediada em São Paulo.

9 DIOGO, Adriano; FERNANDES, Pádua. Pela dignidade dos mortos na cidade de São Paulo! [Entrevista cedida a] Laura Caprigione. São Paulo, 29 jun. 2018. Jornalistas Livres, 2018. http://doi.org/10.26843/ro_unicidv2932017p3. Disponível em: <https://www.facebook.com/watch/?v=795116260612253>. Acesso em: 15 abr. 2020. 
Figura 1. Ato ecumênico organizado no dia 30 de junho pelo Padre Julio Lancelotti e organizações de direitos humanos

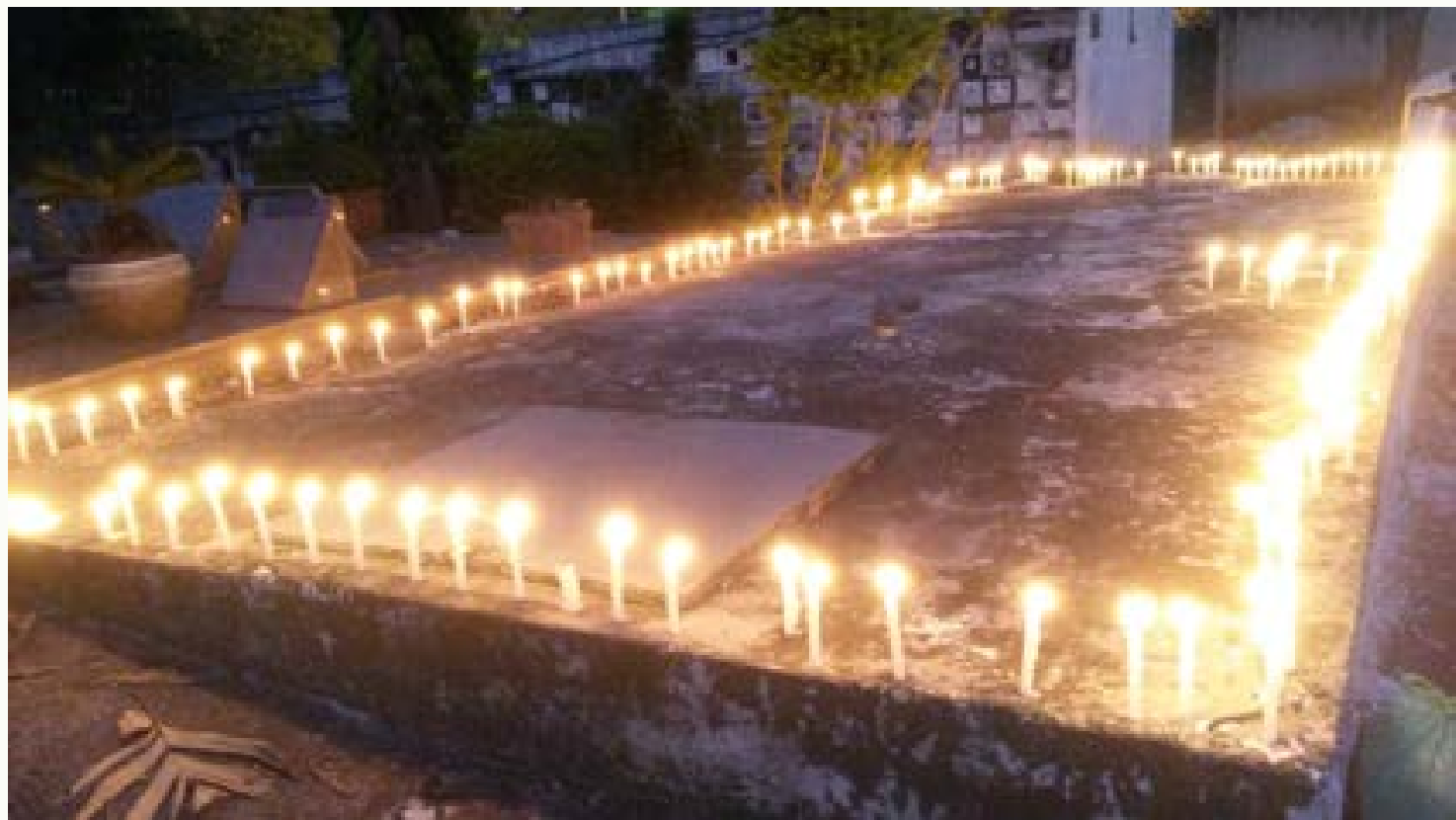

FONTE. Fernandes, Pádua. Nem os mortos estão a salvo: São Paulo, o Cemitério da Quarta Parada e a prefeitura das cinzas. Página de blog "O Palco e o mundo". 07 de julho de 2018.

No caso do estado de emergência e da negação do governo, somada a dificuldades em saber o número de mortos e infectados pela Covid-19 no Brasil, esforços como o Memorial das Vítimas do Coronavírus no Brasil $(2020)^{10}$ são uma maneira de evidenciar essas mortes e de prestar homenagens, individualizando as histórias de cada um.

\section{O cemitério Quarta Parada e as políticas neoliberais}

E a história do João? Enterrado em 1978 com seu nome e sobrenome em uma quadra geral, com os interesses especulativos do cemitério, e classificado como corpo não reclamado anos depois, seus restos mortais foram perdidos no cemitério. O caso de João está relacionado e é sintomático, com o recente interesse do município de São Paulo em cremar em massa os restos mortais que se encontravam no ossário coletivo. Os corpos que estavam ali vieram, como João, da quadra geral e teriam sido classificadas em algum momento como corpo não reclamado. A pesquisa ali desenvolvida buscou levantar elementos para subsidiar os movimentos sociais pediam apoio. Utilizo o estudo de caso como instrumento de análise para compreender a realidade deste fenômeno, para explorar os processos burocráticos e o desaparecimento de identidades por omissão.

Ao entrar no cemitério, a sensação é que não há sequer um pequeno espaço para enterrar mais um corpo, o que foi confirmado pelos sepultadores que lá trabalham. Atualmente, não há possibilidade de comprar novos jazigos. Os funcionários enfatizaram que há uma fila de espera para compra, no caso de disponibilização de novos jazigos. Se há novos enterramentos no Quarta Parada, estão vinculados com pessoas cujo jazigo é propriedade da família. No 
entanto, há interesse neste cemitério, o que pode ser indicado pela tabela de valores para concessão de terrenos nos cemitérios públicos de São Paulo. O metro quadrado no cemitério nível 1, categoria que inclui o Quarta Parada, tem o valor de R\$4.927,15. Para adquirir um jazigo familiar, R\$ 26.000, de acordo com a tabela. Este é um dos cemitérios públicos cujo jazigo é um dos mais caros, assim como em outros cemitérios em bairros ricos. Em comparação, um enterro na quadra geral tem o custo de 132,42 reais.

Esta situação está articulada com os recentes interesses na privatização de cemitérios públicos na cidade de São Paulo. A iniciativa de privatização dos cemitérios e da instituição municipal responsável pela própria gestão integra um projeto político neoliberal empreendido e realizado desde 2017, com a eleição do prefeito João Dória Junior, que criou um gabinete de Privatização (Secretaria de Desestatização). O objetivo deste setor é privatizar as instalações municipais de parques, estádios de futebol, centros de saúde e cemitérios. Esta política de privatização total (Prieto, 2019) tem relação com a emergência de figuras como o tecnocrata despolitizado e "neutro". É o gestor, um empresário que vai transformar as políticas públicas, no caso do município, em uma grande empresa "eficiente". Em fevereiro de 2018, o diretor do cemitério informou o Serviço Funerário que a capacidade do ossário coletivo estava completamente esgotada e continha cerca de 1600 restos humanos de exumações realizadas entre 1941 e 2000, que não foram reclamados pelos familiares ao longo dos anos. A administração do cemitério alegou, ainda, que a cremação era "necessária para a proteção do ambiente, para além de garantir mais espaço para novos funerais". ${ }^{11}$

Todo o processo é problemático, pois além dos interesses especulativos em tornar este cemitério atrativo para os empresários interessados em investir, pois as identidades dos que foram colocados neste ossário não são conhecidas (só constavam sete nomes). Em algum momento dos procedimentos realizados no cemitério, suas identidades perderamse e, portanto, corpos de pessoas não identificadas seriam cremados, como o de João. Intencionalmente, por diferentes reportagens em jornais, uma política para criar a ideia de instituição ineficiente foi levada a cabo com os meios de comunicação social, a partir do roubo de placas de bronze nos jazigos, e outros artefatos no cemitério.

11 G1 SP. Prefeitura de SP consegue na Justiça direito de cremar 1.600 ossadas do Cemitério da Quarta Parada. G1 São Paulo, on-line, 29 jun. 2018. Disponível em: <https://g1.globo.com/sp/sao-paulo/noticia/prefeitura-de-spconsegue-na-justica-direito-de-cremar-1600-ossadas-do-cemiterio-da-quarta-parada.ghtml>. Acesso em: 15 abr. 2020. 


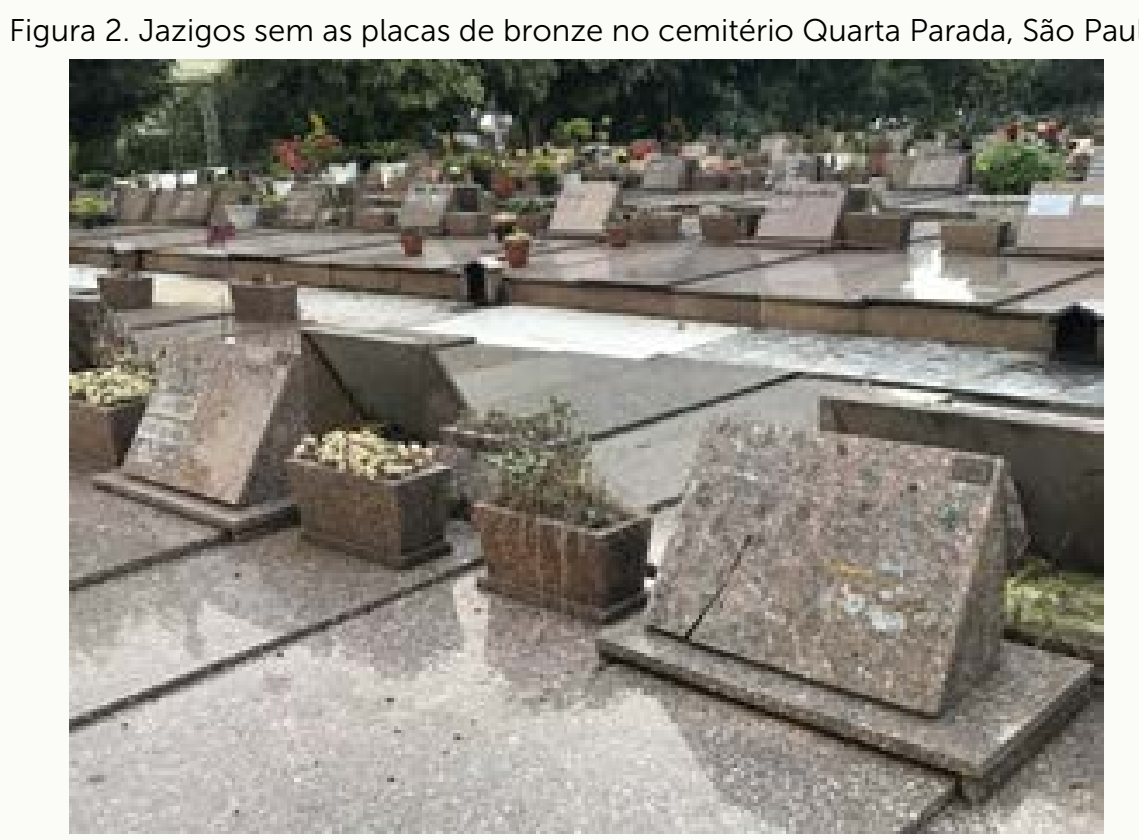

FONTE. Márcia Lika Hattori. Agosto de 2018

Desde a mais alta posição no cemitério até o cidadão que tem ali enterrado seu familiar, a maior parte estava de acordo com a privatização, o que foi evidenciado pelos boletins de ocorrência, recorrentemente realizados pelo diretor, diante dos roubos e, também, pelas reportagens jornalísticas que reforçavam a ineficiência da instituição pública.

Segundo as investigações da Comissão Municipal da Verdade ${ }^{12}$, cujo trabalho foi desenvolvido entre 2014 e 2016, a cremação de corpos desconhecidos ou não reclamados não pode ser feita, pois é contrária aos fundamentos da Constituição Federal de 1988, que afirma que o corpo da pessoa falecida pertence à família. No entanto, tal norma não impede que os restos mortais, quando alocados em ossuários coletivos, ao final do tempo permitido nos túmulos, sejam incinerados, para liberação de espaço livre nos cemitérios municipais. Esta lei nunca foi revogada. O problema consiste na existência de muitos casos em que, por não haver diálogo entre as instituições, associado à forma como o desaparecimento está estruturado em São Paulo ${ }^{13}$ (Hattori et al., 2016; Vendramini Carneiro e Gennari, 2016), na cremação de pessoas cujas identidades não são conhecidas. Assim, o cenário torna-se complexo.

Esta violência, aqui assumida como uma categoria local, relacional e controversa, tem efeitos na produção de direitos, na moral (Eilbaum e Santos, 2015) e nas práticas de intervenção estatal e/ou paraestatal. O legado do caótico sistema burocrático de gestão e acompanhamento da morte torna este tipo de ação - a cremação de ossos humanos não reclamados, com identidades não conhecidas - mais do que problemática.

O caso de João é apenas um, entre as centenas de casos que teriam sido exumados, sem qualquer registro. Corpos enterrados nas quadras gerais que, em certo momento, foram exumados. No entanto, para qual local? Qual o destino, quando se considerou que este corpo

13 SOUZA, Rafael Abreu et al. A formação do grupo de antropologia forense para a identificação das ossadas de Vala de Perus. In: Relatório Final da Comissão Estadual da Verdade Rubens Paiva. 2015. Disponível em: <http:/l comissaodaverdade.al.sp.gov.br/relatorio/tomo-i/parte-i-cap4.html>. Acesso em: 15 abr. 2020. 
não tinha sido reivindicado? Como é possivel que, no caso do João, que tinha identificação, o destino do corpo tenha se perdido? O que é o "corpo não reclamado" nas atividades cotidianas desta instituição?

Entende-se por corpos não reclamados: corpos de pessoas cujas famílias não os reclamaram. Em outras palavras, pessoas sem família, de acordo com a compreensão e legitimação do conceito de família por parte do Estado. Seriam, portanto, os relegados a nenhuma memória ou vínculo, que assim passam à tutela do Estado sobre seu destino. Como outras categorizações sobre cadáveres dotados pelo Estado, o corpo não reclamado é uma construção do próprio poder. Do mesmo modo que é o denominado na burocracia como desconhecido. Não existe uma pessoa desconhecida em uma realidade objetiva, uma pessoa está sempre ligada e rodeada por um contexto social no qual está inserida. O mesmo se pode afirmar em relação ao corpo não reclamado. O que é o corpo não reclamado? É o corpo de alguém que foi abandonado por sua família?

A classificação do corpo não reclamado está inserida nas relações de classe e, portanto, no poder de compra, para ter direito à memória material (Halbwachs, 1997; Baretta, 2015). Não se trata de uma mera classificação administrativa para fins de gestão. É a forma como o Estado governa e classifica e decide os organismos - quem tem direito à memória e a uma genealogia, e quem não tem.

\section{A investigação preliminar forense}

A partir da pesquisa que vem sendo desenvolvida por uma das autoras sobre as técnicas de desaparecimento e as continuidades na gestão da morte da ditadura, e os dias de hoje, foi proposta à Prefeitura uma análise forense sobre as evidências materiais no ossário e a documentação, com o objetivo de levantar dados e entender o processo de uso e ocupação do ossário, considerando a solicitação do Serviço Funerário para cremação de 1600 "ossadas" que estão armazenadas neste lugar. Por que só eram conhecidos sete nomes de pessoas que teriam tido como destino este lugar? Outros objetivos específicos foram:

I. Compreender a composição do ossário coletivo - quando foi criado? Como iniciou sua ocupação? Os corpos eram provenientes de quais locais do cemitério? Quando deixou de ser utilizado este local?

II. Procurar identificar, a partir da documentação dos livros do cemitério, o nome dos corpos que foram para o ossário e os registros relacionados ao envio desses remanescentes humanos no ossário

III. Buscar os registros referentes à cremação realizada em 2005

O trabalho desenvolvido partiu de uma perspectiva da Antropologia Forense, alinhada ao desenvolvimento deste campo na América Latina, que pressupõe a aplicação de teorias, métodos e técnicas da Antropologia Social, Arqueologia, Antropologia Biológica, nos processos 
de buscas e recuperação de cadáveres e de identificação humana, assim como aplicação do esclarecimento dos fatos como apoio ao sistema de administração de justiça e ao trabalho humanitário. Assim, a Antropologia Forense participa ativamente na investigação preliminar, na recuperação dos corpos, na evidência associada e nas análises dos mesmos. ${ }^{14}$

Essa perspectiva latino-americana está profundamente marcada pelos trabalhos de identificação em casos de violações extrajudiciais, desenvolvida na investigação dos contextos ditatoriais da segunda metade do século XX. Mais do que ler ossos ou efetuar uma análise de DNA, compreende-se que a Antropologia Forense conta com diferentes etapas de investigação interligadas, e são fundamentais para compreender as circunstâncias vinculadas ao desaparecimento e morte de uma ou de várias pessoas.

A pesquisa no cemitério Quarta Parada envolveu a análise da documentação dos livros de registro de entrada, um trabalho etnográfico e análise material no ossário coletivo, a partir de uma amostragem de casos. A partir da lista disponibilizada pelo Serviço Funerário, havia o registro de apenas sete corpos, cuja informação indicava como destino o ossário geral da quadra 111.

\section{A compreensão do processo de ocupação e uso da quadra geral e do ossário coletivo}

O trabalho buscou um entendimento do período em que b a quadra geral foi construída e começou a ser ocupada, compreendendo a dinâmica de exumações e reocupações nesta quadra. Contou, também, com uma possível identificação das pessoas, para estabelecer uma lista daqueles que foram alocados no ossário coletivo.

A partir da análise dos livros de registro, com os funcionários do cemitério, o início do uso da quadra geral foi em agosto de 1977. Segundo esta lógica e considerando que os primeiros exumados destinados ao ossário coletivo estavam nesta quadra geral, é possível concluir que ali não há corpos de pessoas enterradas antes do ano de 1977, e não 1940, como veiculado anteriormente. A partir dos registros dos livros, foram coletadas 597 notações de pessoas que foram inumadas na quadra geral e teriam tido como destino, conforme os registros, o ossário geral. Este setor foi criado entre 1995 e 1996, e utilizado inicialmente como destino dos corpos alocados nas quadras gerais, e posteriormente para alguns casos de jazigos familiares, somado a solicitações da prefeitura para exumação de remanescentes humanos ósseos - denominados comícios. Pela documentação, os últimos casos que teriam ido para o ossário seria do último comício em 2006. Uma cremação de casos que não se sabe quais seriam ocorreu ainda em 2005, e não há registros de quais corpos teriam sido cremados, que estavam no ossário.

Se, por um lado, o trabalho possibilitou compreender o processo de uso e ocupação do ossário, ficou evidente a impossibilidade, via documentação, de fazer o caminho de volta, de conhecer pelo menos os nomes das pessoas que estavam destinadas ao ossuário. O estudo

14 ASOCIACIÓN LATINOAMERICANA DE ANTROPOLOGÍA FORENSE. Guía latinoamericana de buenas prácticas para la aplicación en antropología forense. Colombia: Asociación Latinoamericana de Antropología Forense, 2016. 70 p. 
na documentação evidenciou omissão, não cumprimento do destino de inumeráveis corpos que, com certeza foram exumados, só que não se sabe para onde foram destinados. O registro do movimento era falho. Aqueles cujas informações deveriam ter sido alocadas no ossuário somaram o número de 233. Se o ossuário estava completamente ocupado, o mesmo não estava explícito na documentação. Embora fosse difícil associar nos nomes dos corpos com os demais restos e ossos, dependendo das condições de preservação no local, pelo menos seria possível ter conhecimento dos nomes de quem foi ali depositado.

\section{O uso do ossário coletivo}

O ossário coletivo, segundo informações veiculadas, estava com sua capacidade esgotada e "demandava a cremação de 1600 ossadas". Não se sabia ao certo a quantidade de corpos que teriam este local como destino. Para tanto, fizemos uma estimativa de cálculo da população do ossário geral, considerando suas medidas e a capacidade do saco plástico utilizado, com capacidade máxima estimada entre 6.000 a 8.000 sacos, considerando o volume do saco plástico entre 15 e $20 \mathrm{~L}$.

Se, por um lado, a documentação não dialogava com as evidências materiais de um espaço completamente cheio com pelo menos 6000 corpos, quando abrimos o ossário, em um trabalho de amostra das primeiras 50 bolsas, para verificar se havia alguma identificação, apenas nas duas primeiras havia uma etiqueta com as informações dos nomes, provavelmente por terem sido as últimas ali alocadas. Aqueles dois casos em que a etiqueta estava relacionada com as informações do nome da pessoa e a bolsa plástica tinha como destino o ossuário coletivo. No entanto, no caminho de volta, em ambos os casos, não havia qualquer anotação no livro de registro do cemitério. Seja pelo descuido, intencional ou não, a omissão desses registros acarreta impossibilidade de realizar o caminho inverso. Quase todas as bolsas plásticas estavam abertas, de modo que, no processo de deposição, muitos ossos tenham saído de seus sacos.

Esta situação precária do ossário da Quarta Parada não é visível, seja para a população, seja para os empresários interessados em investir. São espaços ocultos, discretas elevações de concreto. Escondidos intencionalmente, dificilmente afetam os olhos da população e menos ainda, do Estado.

O que está sob a terra não está à vista, está escondido para não perturbar nossa relação com a morte. Eles representam aqueles que são negligenciados e têm suas identidades perdidas na instituição - o cemitério. Essa negligência, longe de mero descuido por um ato individual, integra uma política, uma racionalidade governamental, que faz do próprio descuido uma estratégia para fazer desaparecer. 
Figura 3. O ossário coletivo localizado ao lado da quadra 111, antiga quadra geral.

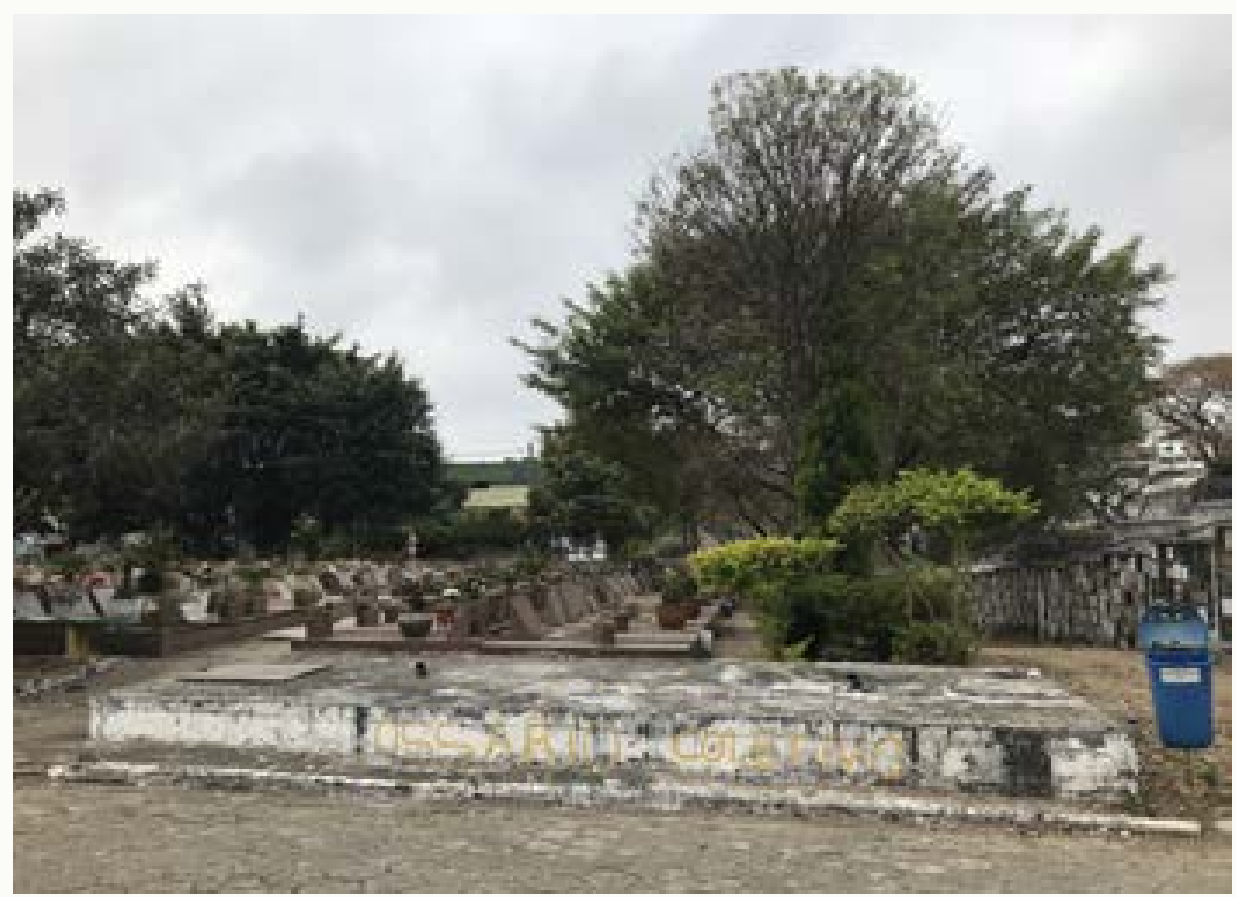

FONTE. Márcia Lika Hattori. Agosto de 2018

\section{Considerações finais}

Buscamos aqui apresentar o caminho da perda da relação entre remanescentes humanos esqueléticos e suas identidades. No processo de exumação e destinação dos corpos não reclamados, evidenciamos como a negligência nos procedimentos na burocracia e acarreta perdas do destino dos corpos. Os interesses empresariais e a possibilidade de privatização dos cemitérios produzem um cenário complexo na gestão do cemitério e dos corpos. A possibilidade de cremação dos corpos não reclamados sem conhecimento de quem são inviabilizaria qualquer possibilidade, nesse cenário caótico, de encontrar uma pessoa que fora exumada e enviada para o ossário coletivo. É certo que, em megalópoles como São Paulo, a superlotação dos cemitérios é uma realidade, em muitos espaços de inumação públicos da cidade, porém os cuidados nos procedimentos necessários para controle e gestão dos corpos são deixados de lado, especialmente no que concerne às classes mais vulneráveis. Desvelar as diferentes formas de omissão é entender uma das formas mais persistentes de desaparecer com corpos.

\section{Agradecimentos}

Este trabalho não seria possivel sem o apoio do incansável Adriano Diogo e das instituições às quais as autoras estão vinculadas. 


\section{Referências bibliográficas}

ABRÃO, Paulo; TORELLY, Marcelo D. Justiça de Transição no Brasil: a dimensão da reparação. In: REPRESSÃO e Memória Política no Contexto Ibero-Brasileiro: Estudos sobre Brasil, Guatemala, Moçambique, Peru e Portugal. Brasília: Ministério da Justiça, 2010. p. 24-59.

ALVES, Jaime Amparo. Topografias da violência: necropoder e governamentalidade espacial em São Paulo. Revista do Departamento de Geografia, São Paulo, v. 22, p. 108-134, 2011. http:// doi.org/10.7154/RDG.2011.0022.0006.

AUGÉ, Marc. Não-lugares: Introdução a uma antropologia da supermodernidade. Campinas, SP: Papirus Editora, 2007. 110 p.

BARAYBAR, José Pablo; BLACKWELL, Rebecca. Where are they? Missing, forensics, and memory. Annals of Anthropological Practice, on-line, v. 38, n. 1, p. 22-42, 2014. http://doi.org/10.1111/ napa.12040.

BARETTA, Jocyane Ricelly. Arqueologia da repressão e da resistência e suas contribuições na construção de memórias. Revista de Arqueologia Pública, Campinas, v. 8, n. 2, p. 76-89, 2014. http://doi.org/10.20396/rap.v8i2.8635640.

BARETTA, Jocyane Ricelly. Arqueologia e a construção de memórias materiais da ditadura militar em Porto Alegre/RS (1964/1985). 2015. Dissertação (Mestrado em História) -Instituto de Filosofia e Ciências Humanas, Universidade Estadual de Campinas, Campinas, 2015. 193 p.

COIMBRA, Cecília Maria Bouças; BRASIL, Vera Vital. Exumando, identificando os mortos e desaparecidos políticos: uma contribuição do GTNM-RJ para o resgate da memória. In: MOURÃO, Janne Calhau (org.). Clínica e Política: subjetividade, direitos humanos e invenção de práticas clínicas. Rio de Janeiro: Abaquar, 2009. v. 2. p. 45-62.

EILBAUM, Lucia; SANTOS, Flavia. M. Quando existe 'violência policial'? Direitos, moralidades e ordem pública no Rio de Janeiro. Revista Dilemas, Rio de Janeiro, v. 8, n. 3, p. 407-428, jul./ set. 2015.

FERREIRA, Letícia Carvalho de Mesquita. Dos autos da cova rasa: a identificação de corpos não identificados no Instituto Médico-Legal do Rio de Janeiro. Rio de Janeiro: E-papers, 2009. 198 p.

GONZÁLEZ RUIBAL, Alfredo. Arqueología de la desaparición. Papeles del CEIC, Leioa, v. 2020, n. 1, p. 1-20, mar. 2020. http://doi.org/10.1387/pceic.20920.

GUPTA, Akhil. Red tape: Bureaucracy, structural violence, and poverty in India. Durham: Duke University Press, 2012. 368 p. http://doi.org/10.1215/9780822394709.

HALBWACHS, Maurice. La mémoire collective. Paris: Albin Michel, 1997. 304 p.

HATTORI, Márcia Lika et al. O caminho burocrático da morte e a máquina de fazer desaparecer: propostas de análise da documentação do Instituto Médico Legal-SP para antropologia forense. Revista do Arquivo, São Paulo, n. 2, p. 1-21, 2016.

HATTORI, Márcia Lika. Regímenes de evidencia y posconflicto: arqueología forense y métodos 
de investigación en el sertão baiano, Brasil. In: ROSIGNOLI, Bruno; MARÍN SUÁREZ, Carlos; TEJERIZO-GARCÍA, Carlos (ed.). Arqueología de la dictadura en Latinoamérica y Europa. Oxford: BAR International Series, 2020. p. 83-93.

KANT DE LIMA, Roberto. A polícia da cidade do Rio de Janeiro: seus dilemas e paradoxos. Rio de Janeiro: Forense, 1995. 266 p.

MAGUIRE, Pedro Pablo Fermin. Desarrollismo, tortura e internación. Vestígios-Revista LatinoAmericana de Arqueologia Histórica, Belo Horizonte, v. 13, n. 2, p. 165-194, 2019. http://doi. org/10.31239/vtg.v2i13.15381.

MEDEIROS, Flavia. "Matar o morto": uma etnografia do Instituto Médico-Legal do Rio de Janeiro. Niterói: Eduff, 2016. 221 p. (Série Antropologia e Ciência Política, v. 57).

PRIETO, Gustavo Francisco Teixeira. São Paulo S/A: privatização, desmanche neoliberal e acumulação urbana de capital. In: LATIN AMERICA STUDIES ASSOCIATION CONFERENCE 2019. Boston: LASA, 2019. Tema: Nuestra America: Justice and Inclusion.

TELES, Edson; SAFATLE, Vladimir Pinheiro (org.). O que resta da ditadura: a exceção brasileira. São Paulo: Boitempo, 2010. 352 p.

TELES, Janaína de Almeida (ed.). Mortos e desaparecidos políticos: reparação ou impunidade? Humanitas. São Paulo, FFLCH/USP, 2001. 386 p.

TELES, Janaína de Almeida. Os familiares de mortos e desaparecidos políticos e a luta por "verdade e justiça" no Brasil. In: TELES, Edson; SAFATLE, Vladimir Pinheiro (org.). O que resta da ditadura: a exceção brasileira. São Paulo: Boitempo, 2010. p. 253-298.

TELES, Maria Amélia de Almeida; LISBOA, Suzana Keniger. A vala de Perus: um marco histórico na busca da verdade e da justiça! In: VALA clandestina de Perus: desaparecidos políticos, um capítulo não encerrado da história brasileira. São Paulo: Ed. do Autor, 2012. p. 51-102.

VALENTE, Rubens. Os fuzis e as flechas: história de sangue e resistência indígena na ditadura. São Paulo: Companhia das Letras, 2017. 518 p.

VENDRAMINI CARNEIRO, Eliana; GENNARI, Patrícia Visnardi. O Ministério Público em busca de pessoas desaparecidas: desaparecimentos forçados por omissão do Estado. Revista Liberdades, São Paulo, n. 22, p. 39-55, maio/ago. 2016.

Recebido em: 22 de abril de 2020

Aprovado em: 15 de outubro de 2020 